\title{
Appearance and potential predictors of poorly controlled hypertension at the primary care level in an urban community
}

This article was published in the following Dove Press journal: Journal of Multidisciplinary Healthcare

\author{
Sawitree Visanuyothin ${ }^{1,2}$ \\ Samlee Plianbangchang ${ }^{2}$ \\ Ratana Somrongthong ${ }^{2}$ \\ 'Social Medicine Department, Maharat \\ Nakhon Ratchasima Hospital, Nakhon \\ Ratchasima, Thailand; ${ }^{2}$ College of \\ Public Health Sciences, Chulalongkorn \\ University, Bangkok, Thailand
}

Purpose: Hypertension (HT) is the major risk factor for cardiovascular diseases because of its poor control. To control HT at the primary care level in urban communities, there is a demand for deeper comprehension of the manifestations of poorly controlled HT. This study aimed to examine appearance of HT, including the association between the appearance and home blood pressure (HBP) control at the primary care level in urban communities.

Patients and methods: A cross-sectional study was conducted in July-October 2017 in an urban community in Thailand. The total sample size from randomization was 125 poorly controlled HT patients who were diagnosed with an average clinic blood pressure $\geq 140 / 90 \mathrm{mmHg}$ in their last three visits. Data were collected by face-to-face interviews, HBP monitoring (HBPM), and blood and urine testing. Data analysis was conducted via descriptive statistics and the chisquare tests, with a significance level of $p<0.05$.

Results: HBPM revealed that $58.4 \%$ of patients with poorly controlled blood pressure from clinic measurement had a systolic blood pressure and diastolic blood pressure that were below the HBP target. Most patients were overweight/obese, but they were nonsmokers and nondrinkers. As comorbidities, they had hyperlipidemia (64.0\%) and diabetes mellitus (53.0\%). One-quarter of them had good levels of knowledge and literacy. Nearly half had good health self-care literacy. Only $13 \%$ exhibited adequate self-management behaviors, but more than half had biochemistry results within normal limits. There were significant associations of smoking history and having hyperlipidemia as a comorbidity with HBP control ( $p=0.010$ and 0.046 , respectively).

Conclusion: The role of HBPM is important in practice when it comes to monitoring HT control at the primary care level in an urban context. Smoking cessation and control of the blood lipid levels should be highlighted not only at the practice, but also at the policy level.

Keywords: characteristics, risk factors, association, home blood pressure, knowledge, health literacy, self-management behaviors, biochemistry

\section{Introduction}

The hypertension (HT) prevalence, undiagnosed HT, untreated HT, and uncontrolled HT rates are higher in low- and middle-income countries than they are in high-income countries. The HT prevalence is increasing because of population growth, aging, and behavioral risk factors. ${ }^{1}$ HT is the major risk for cardiovascular diseases, resulting in coronary heart disease, congestive heart failure, stroke, renal failure, and peripheral arterial disease. ${ }^{2}$ In Thailand, $69.8 \%$ of those who have HT are unaware of their condition. Of those HT patients who have been diagnosed, only $36.6 \%$ are able to control their blood pressure (BP). ${ }^{3}$ There are many predictors associated with poorly controlled HT, such as sex, race, ethnicity, visits to a health clinic per year, and having comorbidities. The most common reason for poorly controlled BP is lack of treatment, the
Correspondence: Samlee Plianbangchang Chulalongkorn University, Institute Phyathai Road, Pathumwan, Bangkok

Tel +66818173530

Email samleep40@gmail.com

Dovepress f in in


second is inadequate treatment, and the third is resistant HT. Patients with poorly controlled BP tend to exhibit infrequent healthcare visits, obesity, chronic kidney disease (CKD), a high Framingham risk score, and infrequent use of spironolactone. ${ }^{4}$ Moreover, nonadherence to treatment in the case of severe poorly controlled HT is associated with a lack of health insurance, inadequate HT knowledge, low education level, cost of discharge medications, and medication nonadherence. ${ }^{5}$ In addition, elevated systolic BP (SBP), diastolic BP (DBP), and uncontrolled HT are associated with increasing body mass index (BMI), waist circumference (WC), low-density lipoprotein (LDL) cholesterol, triglyceride, HbA1c, and C-reactive protein. ${ }^{6}$ Poorly controlled HT is observed more frequently in subjects with increased levels of albuminuria. ${ }^{7}$

HT and coronary patients in urban primary care units (PCUs) who have low levels of health literacy are more likely to have uncontrolled BP than those with higher health literacy. ${ }^{8}$ People with low health literacy have a worse health status and lower life expectancy than they should. ${ }^{9-12}$ Although knowledge improvement may enhance patients' adherence to lifestyle changes and medication, few patients with poor health literacy skills understand the relationship between exercise, dietary salt, body weight, and their BP. ${ }^{13}$ HT control requires antihypertensive drugs for patients who have $\mathrm{BP}$ $\geq 140 / 90 \mathrm{mmHg}$. Furthermore, lifestyle modification is not only important for prevention, but also adjuvant treatment for HT. ${ }^{14-16}$ To control HT, there are many facilitators and barriers related to HT self-management in urban communities. ${ }^{17} \mathrm{~A}$ self-management program based on self-efficacy theory and self-management support is essential for improving patients' self-efficacy in disease management. ${ }^{18,19}$ Moreover, home BP (HBP) measurement is useful not only for diagnosis, but also for treatment evaluation in cases of HT. ${ }^{16,20}$

HBP is a more significant predictor of cardiovascular morbidity and mortality than clinic BP. ${ }^{21}$ However, there is a paucity of studies of poorly controlled HT at the primary care level in urban areas. In addition, the stroke-specific and ischemic heart disease-specific death rates in Thailand doubled from 2002 to $2014,{ }^{22}$ and HT was estimated to be the second leading cause of death in $2009 .{ }^{23}$ To control HT at the primary care level in urban communities via medication and lifestyle modifications, it is necessary to establish a deeper comprehension of the characteristics, knowledge, health literacy, self-management behaviors, adherence, and clinical outcomes of HT patients. This study aimed at examining lifestyle and management knowledge, health literacy, self-management behavior, drug and appointment adherence, and biochemical factors and their association with HBP control to define potential barriers to adequate HT control in patients with poorly controlled HT at the primary care level in an urban community in Thailand.

\section{Methods}

\section{Study area and participants}

A cross-sectional study was conducted in July-October 2017 in an urban community in Muang district, Nakhon Ratchasima province, Thailand. This urban community is located at the center of Muang district, which comprises 66,000 inhabitants. It is under the accountability of five PCUs. Two catchment areas of the PCUs were purposively selected as the study area due to the high population and high prevalence of HT. Cochrane's (1996) formula was used to calculate the sample size, with a $95 \% \mathrm{CI}, p=0.46$, and error $=0.1$. The minimum sample size was 96 , and a final sample size of 125 was determined after adding $30 \%$ to compensate for the expected attrition due to urban context. Recruitment of the sample was performed by a computerized search in a health database and family nurses checking the selection criteria, as follows: age of 30-70 years, registered patient, diagnosed with essential HT, and average clinic BP of $\geq 140 / 90 \mathrm{mmHg}$ on the last three visits. The exclusion criteria were terminal illnesses, psychiatric conditions, postural hypotension, and use of weight loss medication. A sample of 1029 poorly controlled HT patients was randomized by Excel. These individuals were invited to enroll in the study after providing informed consent. Each participant signed a consent form to indicate that they were willing to participate in this study.

\section{Instruments}

Three measurement tools were employed in this study, as follows: 1) questionnaires, 2) blood pressure monitoring (BPM), and 3) biochemical laboratory testing. The adjusted questionnaire comprised the following five sections: 1) demographic data, 2) lifestyle and management knowledge, ${ }^{24} 3$ ) health literacy (adapted from a self-administered questionnaire on Thai people's health literacy level constructed by the Health Systems Research Institute [HSRI] of Thailand), $\left.{ }^{25} 4\right)$ selfmanagement behaviors, ${ }^{26}$ and 5) adherence. ${ }^{27}$ Questions were originally constructed in English and later translated into Thai, except part 3, which was already in the Thai language. Family nurses and related staff at urban PCUs read the questions and edited them to make the language more comprehensible. Following this, the questionnaire was sent to three experts for validity improvement, resulting in a score of 0.8 on the item objective congruence (IOC) index. The IOCs for parts 1, 2, 4, and 5 were $0.8,0.8,0.9$, and 0.7 , respectively. After this review, 
the questionnaire was adjusted and tested for reliability. There were 75 questions, presented as follows: 1) 16 questions on demographic characteristics, 2) 10 questions on lifestyle and management knowledge (nine true/false questions and one multiple choice; Kuder-Richardson 20 (KR-20): 0.607), 3) 20 questions on health literacy (Cronbach's alpha of literacy and potential literacy: 0.960, self-care of chronic patients: 0.861 ), 4) 22 questions on self-management behaviors (Cronbach's alpha: 0.881), and 5) seven questions on drug and appointment adherence (Cronbach's alpha: 0.968).

The questionnaire was applied to collect data via face-toface interviews, which took about 30 minutes. The total possible lifestyle and management score was 10; knowledge was categorized into low $(<6)$, moderate $(6-7)$, and high $(\geq 8) .^{28}$ The total possible score for literacy and potential literacy was 4 , and this was divided into poor (1.1-2.0), fair (2.1-3.0), and good (3.1-4.0). The total possible score for self-care of chronic patients was 10 , but the HSRI does not categorize this score into any groups. ${ }^{25}$ The total possible score for self-management behaviors was 3 , grouped into inadequate $(\leq 2.34)$ and adequate $(>2.34) .{ }^{29}$ The total possible score for drug and appointment adherence was 8 , and this was categorized into nonadherence $(<5.7)$ and adherence $(5.7-8) .{ }^{29}$

HBP monitoring (HBPM) with "the Telehealth Assisted System" was provided to measure BP at home by trained village health volunteers (VHVs). "The URIGHT TD-3128 blood pressure monitoring system" (ESH 2010 approval) with support by "Connect Diagnostics Co. Ltd" was used for BP data collection by VHVs. VHVs performed measurement of BP three times daily in the morning for each patient for 7 consecutive days. BP measurements were taken at patients' homes when they were well rested using the appropriate positioning and suitable BP cuff size. The data from the three measurements were automatically saved in the memory of "the URIGHT TD-3128 blood pressure monitor". In this study, only the second and third measurements were used for an average BP result for each patient. HBPM is better for diagnosing uncontrolled HT compared with clinic BP measurements. ${ }^{20}$ Controlled HBP can be defined as HT patients having an average SBP $<135 \mathrm{mmHg}$ and an average DBP $<85 \mathrm{mmHg}$, as measured by HBPM. ${ }^{16,30}$

Biochemical factors were also measured by using the results from blood and urine tests for LDL-cholesterol, highdensity lipoprotein (HDL) cholesterol (mg/dL), triglycerides $(\mathrm{mg} / \mathrm{dL})$, estimated glomerular filtration rate (GFR), and albuminuria. LDL was divided into normal $(\leq 130 \mathrm{mg} / \mathrm{dL})$ and higher than normal ( $>130 \mathrm{mg} / \mathrm{dL})$. HDL for females was categorized into normal $(\geq 50 \mathrm{mg} / \mathrm{dL})$ and lower than normal
$(<50 \mathrm{mg} / \mathrm{dL})$. HDL for males was categorized into normal ( $\geq 40 \mathrm{mg} / \mathrm{dL})$ and lower than normal ( $<40 \mathrm{mg} / \mathrm{dL})$. Triglycerides was divided into normal $(\leq 150 \mathrm{mg} / \mathrm{dL})$ and higher than normal ( $>150 \mathrm{mg} / \mathrm{dL})$. GFR was calculated by the modification of diet in renal disease, which was used to define patients into five stages of CKD, as follows: stage I, GFR $\geq 90 \mathrm{~mL} /$ $\mathrm{min} / 1.73 \mathrm{~m}^{2}$; stage II, GFR $=60-89 \mathrm{~mL} / \mathrm{min} / 1.73 \mathrm{~m}^{2}$; stage III, GFR=30-59 mL/min $/ 1.73 \mathrm{~m}^{2}$; stage IV, GFR=15-29 mL/ $\mathrm{min} / 1.73 \mathrm{~m}^{2}$; and stage $\mathrm{V}, \mathrm{GFR}<15 \mathrm{~mL} / \mathrm{min} / 1.73 \mathrm{~m}^{2}$. Finally, albuminuria had three categories, namely normoalbuminuria (albumin/creatinine ratio [ACR] $<30 \mathrm{mg} / \mathrm{g}$ of creatinine), microalbuminuria ( $\mathrm{ACR}=30-300 \mathrm{mg} / \mathrm{g}$ of creatinine), and macroalbuminuria (ACR $>300 \mathrm{mg} / \mathrm{g}$ of creatinine).

\section{Data analyses}

Data analyses were conducted by using SPSS statistical package version 16 (SPSS Inc., Chicago, IL, USA). Descriptive statistics, including the percentage, minimum, maximum, mean and SD, and median, were used for the analysis of demographic data, lifestyle and management knowledge, health literacy, self-management behaviors, adherence, and clinical outcomes (SBP/DBP, GFR, triglycerides, HDL, LDL, and albuminuria). Chi-square testing was carried out with a significance level of $p<0.05$.

\section{Ethical considerations}

This study was reviewed and approved by the Institutional Review Boards of the Ethical Committee of Maharat Nakhon Ratchasima Hospital. Each participant provided written informed consent before data collection, HBP measurement, and blood tests for biochemistry. In addition, code names were used to protect the subjects' privacy, and the data were kept confidential.

\section{Results}

One hundred and twenty-five patients were enrolled after informed consent was received. The response rate was $100 \%$. HBPM revealed that $58.4 \%$ of patients with poorly controlled BP from clinic measurements had SBP and DBP values below the target HBP. The number of patients with poor SBP control was twice that of those with poor DBP control. The number of female HT patients was 1.5 times that of male patients. The median age was 63 years. Most HT patients had a WC higher than the normal limit; the average WCs were $89.9 \mathrm{~cm}$ in females and $96.9 \mathrm{~cm}$ in males. Similarly, most of them had BMIs $\geq 23 \mathrm{~kg} / \mathrm{m}^{2}$, where the average BMI was $27.8 \mathrm{~kg} / \mathrm{m}^{2}$. Moreover, nearly all the participants were nonsmokers and most were nondrinkers. Universal coverage (UC) was mostly 
used as their health insurance. They mostly engaged in selfdrug preparation and self-drug taking reminder. Two-thirds of the HT patients lived with their spouses and had sufficient income, with or without savings. Three-quarters had a primary school or less education; two-fifths were unemployed. As comorbidities, the patients had hyperlipidemia (64.0\%), diabetes mellitus (53.0\%), arthritis (12.8\%), renal disease (11.2\%), and peptic ulcer (10.4\%). Women were 1.5 times more likely to have controlled than uncontrolled HT (Table 1).

In terms of literacy, one-quarter of the patients had a good level of understandable verbal communication and hearing voice clearly; however, only $13 \%-14 \%$ had sufficient written communication for others to understand, reading comprehension, and clear vision. Nearly $30 \%$ of the patients perceived that they could perform daily activities and go out by themselves at a good level. Both in terms of experience sharing and self-observation for the health literacy of chronic disease, the percentage of low scores roughly equaled that of high scores. Only about $13 \%$ of the HT patients exhibited adequate self-management behaviors, and one-quarter of them had a high level of knowledge. However, most adhered to drug taking and clinic appointments. Controlled and uncontrolled HT patients had a moderate level of both literacy and potential literacy, but writing and reading abilities showed the lowest scores of all factors. The average health literacy score of uncontrolled HT patients was slightly lower than that of

Table I Comparison of measured characteristics, number and percentage, between controlled and uncontrolled HBP, including their association with HBP control

\begin{tabular}{|c|c|c|c|c|c|}
\hline Parameters & $\begin{array}{l}\text { Controlled } \\
\text { HBP n (\%) }\end{array}$ & $\begin{array}{l}\text { Uncontrolled } \\
\text { HBP n (\%) }\end{array}$ & Total n (\%) & $\chi^{2}$ & $p$-value \\
\hline \multicolumn{6}{|l|}{ Clinic BP $(n=125)$} \\
\hline $\mathrm{SBP} \geq 140 \mathrm{mmHg}$ or $\mathrm{DBP} \geq 90 \mathrm{mmHg}$ & $73(58.4)$ & $52(41.6)$ & - & - & - \\
\hline \multicolumn{6}{|l|}{ Characteristics } \\
\hline \multicolumn{6}{|l|}{$\operatorname{Sex}(n=125)$} \\
\hline Female & $49(67.1)$ & $28(53.8)$ & $77(61.6)$ & 2.263 & 0.132 \\
\hline \multicolumn{6}{|l|}{ Age $(n=|2|)$} \\
\hline$>63$ years & $33(47.1)$ & $22(43.1)$ & $55(45.5)$ & 0.191 & 0.662 \\
\hline \multicolumn{6}{|l|}{ Median $=63$, Min, $\operatorname{Max}=35,70$} \\
\hline \multicolumn{6}{|l|}{ Marital status $(n=125)$} \\
\hline Married and coinhabiting & $44(60.3)$ & $37(7 \mid .2)$ & $81(64.8)$ & 1.576 & 0.209 \\
\hline \multicolumn{6}{|l|}{ Educational level $(n=125)$} \\
\hline Primary school or less & $15(20.5)$ & $18(34.6)$ & $33(26.4)$ & 3.093 & 0.079 \\
\hline \multicolumn{6}{|l|}{ Financial status $(n=123)$} \\
\hline Sufficient income and savings & $17(23.3)$ & $12(24.0)$ & $29(23.6)$ & 1.126 & 0.570 \\
\hline Sufficient income but no savings & $37(50.7)$ & $21(42.0)$ & $58(47.2)$ & & \\
\hline Not enough income or in debt & $19(26.0)$ & $17(34.0)$ & $36(29.3)$ & & \\
\hline \multicolumn{6}{|l|}{ Smoking history $(n=119)$} \\
\hline Nonsmoking & $70(100.0)$ & $44(89.8)$ & I I 4(95.8) & 7.456 & $0.010^{\mathrm{a}, *}$ \\
\hline \multicolumn{6}{|l|}{ Drinking history $(n=|2|)$} \\
\hline Nondrinking & $58(82.9)$ & $36(70.6)$ & 94 (77.7) & 2.562 & 0.109 \\
\hline \multicolumn{6}{|l|}{ Drug-taking management $(n=125)$} \\
\hline Self-drug preparation & $71(97.3)$ & $51(98.1)$ & $122(97.6)$ & 0.086 & 1.000 \\
\hline Self-drug taking reminder & $64(88.9)$ & $51(98.1)$ & $115(92.0)$ & 3.787 & 0.078 \\
\hline \multicolumn{6}{|l|}{ Comorbidity $(n=125)$} \\
\hline Hyperlipidemia & $52(7 \mid .2)$ & $28(53.8)$ & $80(64.0)$ & 3.984 & $0.046 *$ \\
\hline Diabetes mellitus & $42(58.3)$ & $24(46.2)$ & $66(53.2)$ & 1.799 & 0.180 \\
\hline Renal disease & $9(12.3)$ & $5(9.6)$ & $14(11.2)$ & 0.225 & 0.635 \\
\hline Coronary artery disease & $3(4.1)$ & $3(5.8)$ & $6(4.8)$ & 0.183 & 0.183 \\
\hline Cerebrovascular disease & $\mathrm{I}(\mathrm{l} .4)$ & $3(5.8)$ & $4(3.2)$ & 1.856 & 0.308 \\
\hline Atrial fibrillation & $2(1.6)$ & I (1.9) & $3(2.4)$ & 0.093 & 1.000 \\
\hline \multicolumn{6}{|l|}{$\mathrm{BMI}(\mathrm{n}=125)$} \\
\hline$\geq 23 \mathrm{~kg} / \mathrm{m}^{2}$ & $63(86.3)$ & $45(86.5)$ & $108(86.4)$ & 0.001 & 0.970 \\
\hline \multicolumn{6}{|l|}{ Mean $(S D)=27.8(4.4)$, Min, $M a x=18.2,38.1$} \\
\hline \multicolumn{6}{|l|}{ Waist circumference } \\
\hline Female $(n=77) \geq 80 \mathrm{~cm}, \operatorname{Mean}(S D)=89.9(|| .2), \operatorname{Min}, \operatorname{Max}=67.0,123.0$ & $42(85.7)$ & $25(89.3)$ & $67(87.0)$ & 0.201 & 0.472 \\
\hline Male $(n=48) \geq 90 \mathrm{~cm}$, Mean (SD) $=96.9(10.3)$, Min, Max=67.0, II 4.0 & $16(66.7)$ & $19(79.2)$ & $35(72.9)$ & 0.949 & 0.330 \\
\hline
\end{tabular}

Notes: *Significant; ${ }^{2}$ Analyzed by Fisher's Exact Test.

Abbreviations: BMI, body mass index; BP, blood pressure; DBP, diastolic blood pressure; HBP, home blood pressure; Max, maximum; Min, minimum; SBP, systolic blood pressure. 
controlled HT patients in relation to both experience sharing and self-observation. There was no difference in knowledge, behavior, or adherence scores between the controlled and uncontrolled HT patients (Table 2). None of the HT patients had CKD stage IV-V, while $66.1 \%$ had normoalbuminuria. Likewise, more than three-quarters had normal HDL/LDL levels. Half had triglycerides in the normal range (Table 3).

There were significant associations of smoking history, and having hyperlipidemia as a comorbidity, with HBP control ( $p=0.010$ and 0.046 , respectively). The other factors were insignificantly associated with HBP control (Tables 1-3). In terms of knowledge, most HT patients had lifestyle and management knowledge about HT risk, BP interpretation, exercise, dietary approaches to stop hypertension, and a low-salt diet. Nearly half the patients knew about their HT diagnosis. Only one-fifth had correct knowledge about HT complications and medical treatment.

\section{Discussion}

The median age of participants was 63 years, and $61.6 \%$ were female. Most of the participants had excess fat and were overweight/obese. One previous study showed elevated SBP/ DBP and uncontrolled HT are associated with increased BMI and WC. ${ }^{6}$ Most participants in this study did not smoke or drink, engaged in self-drug preparation and self-drug taking reminder, adhered to drug taking and clinic appointments, used the UC scheme, and had a sufficient income. Since UC and other healthcare schemes cover all Thai population and they have benefits in the healthcare package for noncommunicable diseases, this scheme increase health care service accessibility, promotion and prevention in chronic cases, and continuity care. Therefore, UC may lead effects on appearance of patients about smoking, drinking, self-drug management and adherence. In contrast, two studies in urban areas revealed that appointment nonadherence, including a lack of health insurance, insurance without medication coverage, high cost of discharge medications, barriers to appointment attendance, and medication nonadherence were associated with poorly controlled HT. ${ }^{5,8}$ Most participants in this study exhibited poor to fair literacy, low to moderate lifestyle and management knowledge, and inadequate self-management behaviors. Likewise, previous studies have shown that a low level of health literacy ${ }^{8}$ and inadequate HT knowledge ${ }^{5}$ are related to poorly controlled HT. Additionally, Thai foods are salty, sweet, and spicy. Thai eating culture influences their salt consuming behavior, which causes BP elevation/uncontrolled HT. ${ }^{14}$ The number of participants with poor SBP control in the present study is twice that with poor DBP control. This result was similar to that of a study showing that systolic hypertension was the main etiology of poorly controlled HT patients. ${ }^{31}$ In terms of biochemistry, the triglycerides, HDL, and GFR results in this study were comparable to those of a Thai study, although the results for albuminuria were different. ${ }^{7}$ This study found greater percentages of microalbuminuria and macroalbuminuria than the Thai study did, possibly because the Thai study recruited only HT patients without other comorbidities.

Table 2 Comparison of literacy and potential health literacy on chronic disease, lifestyle and management knowledge, self-management behaviors, and drug and appointment adherence between controlled and uncontrolled HBP, including their association with HBP control

\begin{tabular}{|c|c|c|c|c|c|}
\hline Parameter & $\begin{array}{l}\text { Controlled } \\
\text { HBP n (\%) }\end{array}$ & $\begin{array}{l}\text { Uncontrolled } \\
\text { HBP n (\%) }\end{array}$ & $\begin{array}{l}\text { Total } \\
\text { n (\%) }\end{array}$ & $\chi^{2}$ & p-value \\
\hline \multicolumn{6}{|l|}{ Literacy and potential literacy } \\
\hline Good level of writing messages for others to understand $(n=93)$ & $6(11.5)$ & $7(17.1)$ & $13(14.0)$ & 0.932 & 0.628 \\
\hline Good level of reading comprehension $(n=107)$ & $7(11.9)$ & $8(16.7)$ & $15(\mid 4.0)$ & 1.549 & 0.461 \\
\hline Good level of talking to others understandably $(n=125)$ & $16(21.9)$ & $12(23.1)$ & $28(22.4)$ & 2.422 & 0.298 \\
\hline Good level of hearing voice clearly $(n=125)$ & $16(21.9)$ & $11(21.2)$ & $27(21.6)$ & 0.082 & 0.960 \\
\hline Good level of seeing things clearly $(n=125)$ & II (15.0) & $5(9.6)$ & $16(12.8)$ & 1.115 & 0.573 \\
\hline Good level of daily activities $(n=124)$ & $21(28.8)$ & $8(15.7)$ & $29(23.4)$ & 3.118 & 0.210 \\
\hline Good level of going out independently $(n=|2|)$ & $20(27.8)$ & $16(32.7)$ & $36(29.8)$ & 0.392 & 0.822 \\
\hline \multicolumn{6}{|l|}{ Health literacy of chronic disease } \\
\hline High level of experience sharing $(n=125)$ Median=8.0, Min, Max=2.6, 10.0 & $36(49.3)$ & $28(53.8)$ & $64(5 । .2)$ & 0.250 & 0.671 \\
\hline High level of self-observation $(n=125)$ Median=8.0, Min, Max=3.7, 10.0 & $4 \mid(56.2)$ & $26(50.0)$ & $67(53.6)$ & 0.464 & 0.496 \\
\hline \multicolumn{6}{|l|}{ High level of lifestyle and management knowledge $(n=122)$} \\
\hline Median=8.0, Min, Max=0, 9.0 & $19(27.1)$ & II (2I.2) & $30(24.6)$ & 2.120 & 0.346 \\
\hline \multicolumn{6}{|l|}{ Adequate self-management behavior level $(n=125)$} \\
\hline Mean $(\mathrm{SD})=2.4(0.3), \operatorname{Min}, \operatorname{Max}=1.7,3.1$ & $12(16.4)$ & $4(7.7)$ & $16(12.8)$ & 2.081 & 0.149 \\
\hline \multicolumn{6}{|l|}{ Drug and appointment adherence $(n=122)$} \\
\hline Median=7.0, Min, Max=3.0, 8.0 & $65(91.5)$ & $45(88.2)$ & $110(90.2)$ & 0.368 & 0.544 \\
\hline
\end{tabular}

Abbreviations: HBP, home blood pressure; Max, maximum; Min, minimum. 
Table 3 Comparison of biochemical results between controlled and uncontrolled HBP, including their association with HBP control

\begin{tabular}{|c|c|c|c|c|c|}
\hline Parameter & $\begin{array}{l}\text { Controlled } \\
\text { HBP n (\%) }\end{array}$ & $\begin{array}{l}\text { Uncontrolled } \\
\text { HBP n (\%) }\end{array}$ & $\begin{array}{l}\text { Total } \\
\text { n (\%) }\end{array}$ & $\chi^{2}$ & $p$-value \\
\hline \multicolumn{6}{|l|}{ Chronic kidney disease $(n=125)$} \\
\hline Stage I (GFR $\left.\geq 90 \mathrm{~mL} / \mathrm{min} / \mathrm{l} .73 \mathrm{~m}^{2}\right)$ & $23(3 \mid .5)$ & $19(36.5)$ & $42(33.6)$ & 0.362 & 0.843 \\
\hline Stage II (GFR=60-89 mL/min/l.73 m²) & $40(54.8)$ & $26(50.0)$ & $66(52.8)$ & & \\
\hline Stage III (GFR=30-59 mL/min/I.73 m²) & $10(13.7)$ & $7(13.5)$ & $17(13.6)$ & & \\
\hline \multicolumn{6}{|l|}{ Median=82.0, Min, Max=5.0, II5.0 } \\
\hline \multicolumn{6}{|l|}{ Triglycerides $(n=125)$} \\
\hline$\leq 150 \mathrm{mg} / \mathrm{dL}$ & $36(49.3)$ & $25(48.1)$ & $61(48.8)$ & 0.019 & 0.891 \\
\hline$>150 \mathrm{mg} / \mathrm{dL}$ & $37(50.7)$ & $27(51.9)$ & $64(5 । .2)$ & & \\
\hline \multicolumn{6}{|l|}{ Median $=180.0$, Min, Max $=61.0,|1| 88.0$} \\
\hline \multicolumn{6}{|l|}{ HDL in females $(n=77)$} \\
\hline$\geq 50 \mathrm{mg} / \mathrm{dL}$ & $33(67.3)$ & $24(85.7)$ & $57(74.0)$ & 3.126 & 0.077 \\
\hline$<50 \mathrm{mg} / \mathrm{dL}$ & $16(32.7)$ & $4(14.3)$ & $20(26.0)$ & & \\
\hline \multicolumn{6}{|l|}{ Median=59.5, Min, Max=38.0, 109.0} \\
\hline \multicolumn{6}{|l|}{ HDL in males $(n=48)$} \\
\hline$\geq 40 \mathrm{mg} / \mathrm{dL}$ & 22 (9l.7) & $21(87.5)$ & $43(89.6)$ & 0.223 & 1.000 \\
\hline$<40 \mathrm{mg} / \mathrm{dL}$ & $2(8.3)$ & $3(12.5)$ & $5(10.4)$ & & \\
\hline \multicolumn{6}{|l|}{ Median $=51.8$, Min, $\operatorname{Max}=28.0,88.0$} \\
\hline \multicolumn{6}{|l|}{$\operatorname{LDL}(n=123)$} \\
\hline$\leq 130 \mathrm{mg} / \mathrm{dL}$ & $53(74.6)$ & $33(63.5)$ & $86(69.9)$ & 1.786 & 0.181 \\
\hline$>130 \mathrm{mg} / \mathrm{dL}$ & $18(25.4)$ & $19(36.5)$ & $37(30.1)$ & & \\
\hline \multicolumn{6}{|l|}{ Mean $(S D)=|| 3.2(3 \mid .8), \operatorname{Min}, \operatorname{Max}=4 \mid .0,207.0$} \\
\hline \multicolumn{6}{|l|}{ Albuminuria $(n=124)$} \\
\hline Normoalbuminuria & $48(66.7)$ & $34(65.4)$ & $82(66.1)$ & 2.665 & 0.264 \\
\hline Microalbuminuria & $20(27.8)$ & II (2I.2) & $31(25.0)$ & & \\
\hline Macroalbuminuria & $4(5.6)$ & $7(13.5)$ & II (8.9) & & \\
\hline Median $=|6.5|$, Min, Max=2.70, 743.4 $\mid$ & & & & & \\
\hline
\end{tabular}

Abbreviations: GFR, glomerular filtration rate; HBP, home blood pressure; HDL, high-density lipoprotein; LDL, low density lipoprotein; Max, maximum; Min, minimum.

From the 125 participants defined as having poorly controlled HT using the average clinic BP, $41.6 \%$ were found to have poorly controlled HT using the average HBP measurement. This correlated with a study performed in the inner city of London, in which half of the poorly controlled HT patients had BPs lower than the target when measured using the HBPM compared with the clinic BP control group. ${ }^{32}$ HT diagnosis should be based on clinic BP measured on at least two different occasions. HBPM and ambulatory BP monitoring have been recommended for use as complements to clinic BP for the diagnosis of HT. ${ }^{16,30}$ However, one study revealed that HBPM is superior to clinic BP measurement for the diagnosis of poorly controlled HT, as well as for the assessment of antihypertensive drug effects and patients' compliance and HT control. ${ }^{30}$

The results of this study demonstrated the significant associations of smoking history and having hyperlipidemia with HBP control. Cigarette smoking has a considerable role in the inflammation and oxidative stress that arise during arteriosclerosis development. ${ }^{33}$ Similarly, LDL increases local and systematic inflammation, monocyte adhesion, endothelial cell dysfunction and apoptosis, and smooth muscle cell proliferation, leading to atherosclerotic plaque. ${ }^{34}$ Consequently, atherosclerosis plays an important role in poorly controlled HT. Moreover, both dyslipidemia and HT cause endothelium damage, which results in a loss of vasomotor activity, disproportionate vascular contractility, and elevation of BP in dyslipidemic patients, while BP elevation occurs in HT patients, like a vicious circle. This phenomenon aggravates the development and progression of arteriosclerosis. ${ }^{35}$

\section{Conclusion}

The findings of this study presented the characteristics of poorly controlled HT and their association with HBP control at the primary care level in an urban community. The HBPM revealed that two-fifths of patients with poorly controlled BP from clinic measurements had poorly controlled HBP. Most were overweight/obese, and more than half had hyperlipidemia and diabetes mellitus as comorbidities. They had low levels of knowledge, literacy, and adequate self-management behaviors. The factors significantly associated with HBP control were smoking history and hyperlipidemia. However, 
causal relationship between those factors with HBP control cannot be defined, which is the general limitation of crosssectional study. This study has underlined HBPM's and VHVs' roles in practice in terms of monitoring HT control at the primary care level in an urban context in a low- to middle-income country. Controlling HT requires more than focusing on HT control itself; smoking cessation and blood lipid level control, especially that of LDL, should not only be a focus in practice, but also at the policy level. Additionally, health education concerning HT knowledge in urban communities requires more emphasis on HT complications and medical treatment. Further research should focus on creation and testing the effectiveness of a program to improve HBP in poorly controlled HT at the primary care level in an urban community.

\section{Acknowledgments}

The authors are sincerely grateful to Maharat Nakhon Ratchasima Hospital for funding this study and acknowledge the partial support from Chulalongkorn University for providing the 90th Anniversary Chulalongkorn University Fund for Doctoral Scholarship, as well as all respondents and PCUs under Maharat Nakhon Ratchasima Hospital for their cooperation.

\section{Disclosure}

The authors report no conflicts of interest in this work.

\section{References}

1. World Health Organization (WHO). A Global Brief on Hypertension Silent Killer, Global Public Health Crisis. Geneva, Switzerland: WHO; 2013.

2. Kotchen TA. Hypertensive Vascular Disease. In: Dennis Kasper AF, Stephen Hauser, Dan Longo, J. Larry Jameson, Joseph Loscalzo, editor. Harrison's Principles of Internal Medicine. 19th ed. New York: McGraw-Hill; 2015.

3. Aekplakorn W, Abbott-Klafter J, Khonputsa P, et al. Prevalence and management of prehypertension and hypertension by geographic regions of Thailand: the Third National Health Examination Survey, 2004. J Hypertens. 2008;26(2):191-198.

4. Basile JN, Bloch MJ. NHANES data highlight the clinical characteristics of those with poorly controlled hypertension. J Clin Hypertens (Greenwich). 2012;14(4):267-268.

5. Nwabuo CC, Dy SM, Weeks K, Young JH. Factors associated with appointment non-adherence among African-Americans with severe, poorly controlled hypertension. PLoS One. 2014;9(8):e103090.

6. Thoenes M, Bramlage P, Zhong S, Shang S, Volpe M, Spirk D. Hypertension control and cardiometabolic risk: a regional perspective. Cardiol Res Pract. 2012;2012:1-11.

7. Gojaseni P, Phaopha A, Chailimpamontree W, Pajarey T, Chittinandana A. Prevalence and risk factors of microalbuminuria in Thai nondiabetic hypertensive patients. Vasc Health Risk Manag. 2010;6:157-165.

8. McNaughton CD, Jacobson TA, Kripalani S. Low literacy is associated with uncontrolled blood pressure in primary care patients with hypertension and heart disease. Patient Educ Couns. 2014;96(2):165-170.
9. Andrew P. Health literacy around the world: Part 1 health literacy efforts outside of the United States: Institute of Medicine Roundtable on Health Literacy; 2012.

10. Mayagah K, Wayne M. A working document for discussion at the 7th Global Conference on Health Promotion, "Promoting Health and Development: Closing the Implementation Gap", Nairobi, Kenya, 26-30 October 2009: WHO; 2009 [cited 2014200314]. Available from: http:// www.who.int/healthpromotion/conferences/7gchp/Track1_Inner.pdf. Accessed November 22, 2017.

11. Kickbusch I, Pelikan JM, Apfel F, Tsouros AD, World Health Organization. Regional Office for Europe. Health literacy: The Solid Facts. Copenhagen: WHO Regional Office for Europe; 2013:86.

12. Nutbeam D. Health literacy as a public health goal: a challenge for contemporary health education and communication strategies into the 21st century. Health Promot Int. 2000;15(3):259-267.

13. Safeer RS, Cooke CE, Keenan J. The impact of health literacy on cardiovascular disease. Vasc Health Risk Manag. 2006;2(4):457-464.

14. Kotchen TA. Hypertensive vascular disease. In: Kasper D, Fauci A, Hauser S, Longo D, Jameson JL, Loscalzo J, editors. Harrison's Principles of Internal Medicine. 19th ed. USA, McGraw-Hi11 Education; 2015:1611-1627.

15. James PA, Oparil S, Carter BL, et al. 2014 evidence-based guideline for the management of high blood pressure in adults report from the panel members appointed to the Eighth Joint National Committee (JNC 8). JAMA. 2014;311(5):507-520.

16. Kario K. Key points of the Japanese Society of Hypertension Guidelines for the Management of Hypertension in 2014. Pulse (Basel). 2015;3(1):35-47.

17. Flynn SJ, Ameling JM, Hill-Briggs F, et al. Facilitators and barriers to hypertension self-management in urban African Americans: perspectives of patients and family members. Patient Preference and Adherence. 2013;7:741-749.

18. Jang Y, Yoo H. Self-management programs based on the social cognitive theory for Koreans with chronic disease: a systematic review. Contemp Nurse. 2012;40(2):147-159.

19. Battersby M, Martin A, Hood C, et al. Educating Future Health Care Professionals to Support People with Chronic Conditions to Live Better and Live Longer. Australia: Flinders Human Behaviour and Health Research Unit (FHBHRU); 2007.

20. Stergiou GS, Bliziotis IA. Home blood pressure monitoring in the diagnosis and treatment of hypertension: a systematic review. Am J Hypertens. 2010;24(2):123-134.

21. Warda AM, Takahashib O, Stevensa R, Heneghana C. Home measurement of blood pressure and cardiovascular disease: systematic review and meta-analysis of prospective studies. $J$ Hypertens. 2012;30(3): 449-456.

22. The important cause specific death rate in Thailand: Office of the National Economics and Social Development Board; [30/04/16]. Available from: https://www.m-society.go.th/article_attach/15737/18923.pdf. Accessed April 30, 2016.

23. Juthamat Kunnathum, Nuttapat Makka, Suchunya Aungkulanon, Chakvida Amornvisaisoradej, Kanitta Bundhamcharoen. A comparative risk assessment of health burden attributable to modifiable risk factors in Thailand, 2009: a systematic analysis. Lancet. 2013;381(S78).

24. Schapira M. Fletcher KE, Hayes A, et al. The Development and Validation of the Hypertension Evaluation of Lifestyle and Management Knowledge Scale. J Clin Hypertens (Greenwich). 2012;14(7):461-466.

25. Health Literacy Survey in Sample Population for Validity Testing by Psychometric Method (Thai Language) [Internet]. Health System Research Institute (HSRI). 2013 [cited 8/10/17]. Available from: http:// old.hsri.or.th/media/1301. Accessed October 8, 2017.

26. Han HR, Lee H, Commodore-Mensah Y, Kim M. Development and validation of the hypertension self-care profile a practical tool to measure hypertension Self-care. J Cardiovasc Nurs. 2014;29(3):E11-E20.

27. Jankowska-Polanska B, Uchmanowicz I, Chudiak A, Dudek K, Morisky DE, Szymanska-Chabowska A. Psychometric properties of the Polish version of the eight-item Morisky Medication Adherence Scale in hypertensive adults. Patient Prefer and Adherence. 2016;10:1759-1766. 
28. Bloom BS. Learning for Mastery. Eval Comment. 1968;1(2):1-5.

29. Bernard R. Chapter 2 descriptive statistics. In: Rosner B, editor. Fundamental of Biostatistics Seventh Edition. 5th ed. USA: Duxbury; 2000:7-44.

30. Parati G, Stergiou GS, Asmar R, et al. European society of hypertension practice guidelines for home blood pressure monitoring. J Hum Hypertens. 2010;24(12):779-785.

31. Alam MG, Barri YM. Systolic blood pressure is the main etiology for poorly controlled hypertension. Am J Hypertens. 2003;16(2):140-143.

32. Dean SC, Kerry SM, Cappuccio FP, Oakeshott P. Pilot study of potential barriers to blood pressure control in patients with inadequately controlled hypertension. Fam Pract. 2007;24(3):259-262.
33. Chmielewska K, Formanowicz D, Formanowicz P. The effect of cigarette smoking on endothelial damage and atherosclerosis development - modeled and analyzed using Petri nets. Arch Control Sci. 2017;27(2):211-228.

34. Helkin A, Stein JJ, Lin S, Siddiqui S, Maier KG, Gahtan V. Dyslipidemia Part 1-Review of lipid metabolism and vascular cell physiology. Vasc Endovascular Surg. 2016;50(2):107-118.

35. Hurtubise J, McLellan K, Durr K, Onasanya O, Nwabuko D, Ndisang JF. The different facets of dyslipidemia and hypertension in atherosclerosis. Curr Atheroscler Rep. 2016;18(12):82.
Journal of Multidisciplinary Healthcare

\section{Publish your work in this journal}

The Journal of Multidisciplinary Healthcare is an international, peerreviewed open-access journal that aims to represent and publish research in healthcare areas delivered by practitioners of different disciplines. This includes studies and reviews conducted by multidisciplinary teams as well as research which evaluates the results or conduct of such teams or health care processes in general. The journal covers a very wide range of areas and welcomes submissions from practitioners at all levels, from all over the world. The manuscript management system is completely online and includes a very quick and fair peer-review system. Visit http://www.dovepress.com/ testimonials.php to read real quotes from published authors. 